\title{
Olfactory Dysfunction in Familial and Sporadic Parkinson's Disease
}

\author{
Bruce A. Chase ${ }^{1 *}$ and Katerina Markopoulou ${ }^{2,3}$ \\ ${ }^{1}$ Department of Biology, University of Nebraska at Omaha, Omaha, NE, United States, ${ }^{2}$ Department of Neurology, \\ NorthShore University HealthSystem, Evanston, IL, United States, ${ }^{3}$ Department of Neurology, University of Chicago, \\ Chicago, IL, United States
}

\section{OPEN ACCESS}

Edited by:

Andrew Anthony Hicks,

Eurac Research, Italy

Reviewed by:

Shinsuke Fujioka,

Fukuoka University, Japan

Kenya Nishioka,

Juntendo University, Japan

*Correspondence:

Bruce A. Chase

bchase@unomaha.edu

Specialty section: This article was submitted to Neurogenetics,

a section of the journal

Frontiers in Neurology

Received: 28 February 2020 Accepted: 27 April 2020

Published: 29 May 2020

Citation:

Chase BA and Markopoulou K (2020) Olfactory Dysfunction in Familial and Sporadic Parkinson's Disease. Front. Neurol. 11:447 doi: 10.3389/fneur.2020.00447
This minireview discusses our current understanding of the olfactory dysfunction that is frequently observed in sporadic and familial forms of Parkinson's disease and parkinsonian syndromes. We review the salient characteristics of olfactory dysfunction in these conditions, discussing its prevalence and characteristics, how neuronal processes and circuits are altered in Parkinson's disease, and what is assessed by clinically used measures of olfactory function. We highlight how studies of monogenic Parkinson's disease and investigations in ethnically diverse populations have contributed to understanding the mechanisms underlying olfactory dysfunction. Furthermore, we discuss how imaging and system-level approaches have been used to understand the pathogenesis of olfactory dysfunction. We discuss the challenging, remaining gaps in understanding the basis of olfactory dysfunction in neurodegeneration. We propose that insights could be obtained by following longitudinal cohorts with familial forms of Parkinson's disease using a combination of approaches: a multifaceted longitudinal assessment of olfactory function during disease progression is essential to identify not only how dysfunction arises, but also to address its relationship to motor and non-motor Parkinson's disease symptoms. An assessment of cohorts having monogenic forms of Parkinson's disease, available within the Genetic Epidemiology of Parkinson's Disease (GEoPD), as well as other international consortia, will have heuristic value in addressing the complexity of olfactory dysfunction in the context of the neurodegenerative process. This will inform our understanding of Parkinson's disease as a multisystem disorder and facilitate the more effective use of olfactory dysfunction assessment in identifying prodromal Parkinson's disease and understanding disease progression.

Keywords: olfactory dysfunction, genetics, idiopathic Parkinson's disease, longitudinal studies, biomarker, cognition, monogenic Parkinson's disease, neurodegeneration

\section{INTRODUCTION}

Since Ansari and Johnson (1) first reported that olfactory dysfunction (OD) occurs in Parkinson's disease (PD), OD has been evaluated using tests of odor identification, odor discrimination, odor-threshold detection and electrophysiology (2-4). OD is not PD-specific and is prevalent in aging and other diseases, particularly in neurodegenerative disorders such as Alzheimer's disease, Huntington's disease, and rapid-eye-movement sleep-behavior disorder (5-12). OD can severely impact the quality of life, affecting interpersonal and eating habits, patient safety, and nutritional intake $(13-15)$. Because OD is prominent in $\mathrm{PD}(16,17)$ and its onset may signal prodromal PD, 
it is important to understand how and when OD arises, the mechanisms underlying its association with $\mathrm{PD}$ progression, and identify interventions for OD.

\section{OD PREVALENCE IN PD}

Cross-sectional studies revealed that OD occurs in sporadic PD prior to the initiation of dopaminergic therapy [reviews: $(3,4,18-20)]$. The reported prevalence of OD in sporadic PD varies substantially: $45-50 \%(1,21,22), 70-80 \%(2,23)$, and $90-$ $97 \%(24,25)$. This may reflect challenges in PD diagnosis, OD measurement, sample size, normative group selection, and age. Prevalence of OD generally decreases when adjusted for agerelated norms, as the prevalence of OD is over $50 \%$ past age 65 and $62-80 \%$ past age $80(26,27)$.

Interestingly, $\mathrm{OD}$ in monogenic $\mathrm{PD}$ exhibits variable penetrance and expressivity. In manifesting carriers with GBA ( $\beta$-glucosylceramidase), SNCA ( $\alpha$-synuclein, point or gene-multiplication), LRRK2 (leucine-rich repeat kinase 2), PINK1 (PTEN-induced kinase 1), or DJ1 (PARK7: Parkinsonism-associated deglycase) mutations, and in MAPT (microtubule-associated protein tau)-associated frontotemporal dementia and parkinsonism, OD-penetrance overlaps with that in sporadic PD [(28-64); reviews: $(3,65-68)]$. While different studies report varying, sex- or allele-differential OD prevalence in mutation carriers relative to sporadic PD controls [tabulated in Doty (3)], two key OD features seen in sporadic PD persist in many monogenic forms. First, while many carriers are hyposmic when they phenoconvert to show motor symptoms, some carriers have mostly preserved olfaction $(28,40)$. Second, the distribution of $\mathrm{OD}$ in monogenic PD cohorts is similar to sporadic PD (Figure 1). The striking exception is PRKN (parkin RBR E3-ubiquitin protein ligase) and VPS35 (VPS35 retromer-complex component) manifesting carriers, who have normal olfaction or only mild OD (70-75). As discussed below, the preserved olfaction in $P R K N$ carriers and possibly some subsets of LRRK2 carriers appears related to an absence of Lewy bodies (LBs) in the olfactory bulb and/or the olfactory system (76-78).

Mutations in LRRK2, PINK1, GBA, SNCA, and PRKN have similar effects on OD across ethnically and geographically diverse populations. Hence, if a mutation causes OD, its effect-size on OD-related neurodegenerative processes is large relative to genetic background and environmental exposure. Since these mutations increase substantially PD risk, targeted investigations of non-manifesting mutation carriers of LRRK2, PINK1, GBA, and SNCA provide a unique opportunity to understand OD in PD.

\section{OD CHARACTERISTICS IN PD}

Though many fundamental questions about $\mathrm{OD}$ in $\mathrm{PD}$ have been raised for some time $(24,79,80)$ and studied in diverse patient cohorts and contexts, consensus answers are not always available, as described below. Sometimes, conflicting findings reflect the tests used or their interpretation. As discussed more fully by

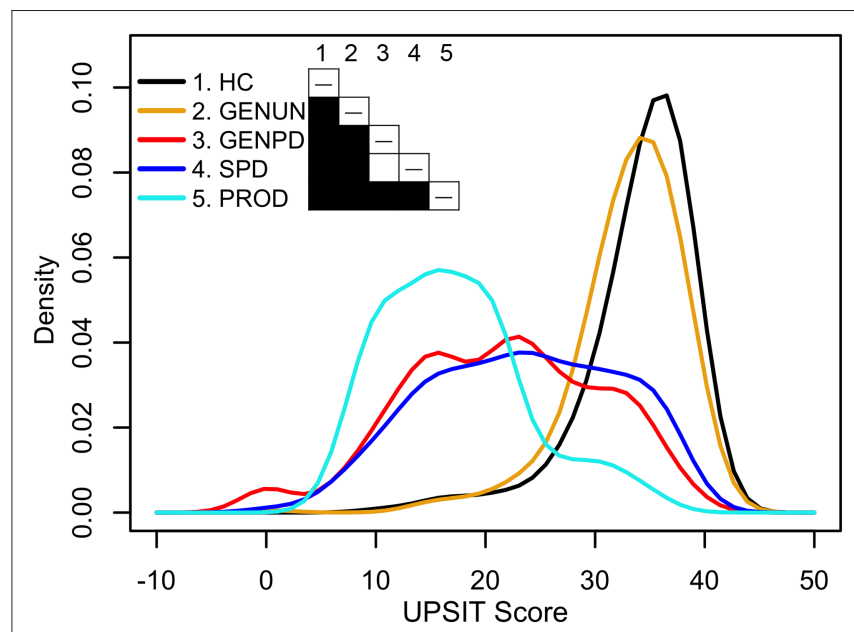

FIGURE 1 | Univariate density estimates of scores on the University of Pennsylvania Smell Identification Test (UPSIT) in five PPMI cohorts (69). Cohorts: 198 healthy controls (HC, black) age-matched with 491 sporadic Parkinson's disease patients (SPD, blue, $\geq 2$ of resting tremor, bradykinesia, or rigidity, with resting tremor or bradykinesia required, or either asymmetric resting tremor or asymmetric bradykinesia; PD diagnosis $\leq 2$ years; Hoehn and Yahr stage I-II; scan-confirmed dopaminergic deficit; $\geq 30$ years at diagnosis; no dopaminergic medications $\geq 6$ months after baseline assessment), 310 asymptomatic genetic Parkinson's disease patients who have a mutation, or are a first-degree relative of an individual having a mutation, in LRRK2, SNCA, or GBA (GENUN, gold), 220 symptomatic genetic Parkinson's disease patients who have a mutation in LRRK2, SNCA, or GBA (GENPD, red), and 61 individuals selected for REM-behavior sleep disorder and/or hyposmia (PROD, cyan). Shading in the table cells indicates the $P$-value (white: $P \geq 0.05$, black: $P<0.001$ ) obtained from pairwise non-parametric bootstrap tests of equal densities using 1,000 permutations.

Doty (81), while the results on psychophysical tests of OD (tests of odor identification, odor discrimination, or odor-threshold detection) are strongly correlated, they vary in reliability and sensitivity and assess different neurophysiological, neurological, and/or psychological aspects. Most often, OD is evaluated using tests of odor identification. Using those tests, variable OD is seen in all studies of sporadic PD and those monogenic $\mathrm{PD}$ forms resembling sporadic $\mathrm{PD}$ (SNCA, GBA, LRRK2), including at motor-symptom onset. Figure 1 (69) illustrates this using univariate density estimates of odor-identificationtest scores obtained from the Parkinson's Progression Marker Initiative (PPMI). While the score distributions of early-stage, dopamine-transporter-scan positive, dopaminergic-treatment naïve sporadic PD (blue), and age-matched healthy controls (black) are distinct, both groups have normosmic, hyposmic, and anosmic membership. This is also observed in manifesting $S N C A, G B A$, and LRRK2 carriers (red line), which here have a score distribution like sporadic PD. Indeed, anosmia is not always seen in manifesting carriers in nuclear families with monogenic $\operatorname{PD}(28,52)$. Hence, like PD motor symptoms, OD has variable penetrance in sporadic and some monogenic PD. Unlike them, $\mathrm{OD}$ is frequently seen in otherwise healthy aging and other neurodegenerative diseases, suggesting that OD can result from a confluence of processes. 
Though OD in PD presents non-uniformly, community-based prospective studies demonstrated that it can appear up to 4 years before motor-symptom onset $(79,80)$; in MAPT carriers it can appear 2 years before symptom onset (52). Consequently, OD has been used in biomarker panels for predicting risk and/or progression of PD [(59, 82-88); reviews: $(18,19,89-91)]$. For this purpose, it is important to elucidate: (1) whether OD in PD is distinguishable from OD in other diseases and aging; (2) how its onset and progression relates to motor-symptom onset and progression; (3) whether OD severity is associated with disease stage, duration, or predicts disease progression; and (4) what clinical tests of OD measure in the context of the disease process. Well-designed studies of OD in monogenic PD can address each issue.

\section{DISTINGUISHING FEATURES OF OD IN PD}

Central to understanding whether the etiology of OD in PD is shared with that in the elderly or other neurodegenerative diseases is identifying whether OD has PD-specific characteristics. PD does affect supra-threshold estimates of perceived odor intensity, which appears spared in Alzheimer's disease, schizophrenia, and the elderly (92), but does not affect the trigeminal system (93). Combined with imaging, it can help distinguish disorders whose initial presentation overlaps with PD, such as progressive supranuclear palsy, cortico-basal degeneration, or multiple system atrophy [(94-96); reviews: $(20,97)]$.

Many studies have identified a set of odors or pattern of OD that best evaluates OD in their cohort (98-107). Most often however, the odor sets are dissimilar in different PD populations (108). This likely reflects odor identification being influenced strongly by prior exposure and population variation in odorantreceptor alleles. Multiple analyses have indicated that there is not odor-selective hyposmia in PD. Highly compelling is an odor-item analysis indicating that the discriminatory power of odor subsets is not shared across independently selected groups (109). Additional support comes from longitudinally evaluating hyposmia in subjects with sporadic PD, subjects without neurodegenerative disease, and in MAPT-mutation carriers. They reveal odor-identification irreproducibility as a general feature of OD: subjects do not misidentify the same odors on replicate odor-identification tests (52). In a longitudinal study of sporadic or monogenic PD subjects recruited from ethnically diverse populations, comparison of results across populations would be facilitated by using a universal olfactory test that is independent of odor-specific insensitivity or prior experience (110).

\section{HOW IS OD RELATED TO DISEASE ONSET AND PROGRESSION?}

The etiological mechanisms underlying the variable presentation of both PD motor symptoms and OD remain unclear. The olfactory epithelium in PD appears normal (111), but it is unknown whether PD impacts its neurogenic niche (112), the functional integration of axons from differentiating olfactoryreceptor neurons into the olfactory bulb, and how either process impacts OD. $\alpha$-Synuclein deposits are found in the olfactory bulb and anterior olfactory nucleus at Braak stage I (113-115), and glomerular volume is reduced by half in PD (116). Since the olfactory bulb plays a critical role in the spatiotemporal coding of smell, OD early in disease might reflect the incomplete inhibition of olfactory inputs at the level of the olfactory bulb (117) and the reported increase in dopaminergic neurons $(118,119)$. Studies of OD in monogenic PD offer a compelling hypothesis for the variable expressivity of $\mathrm{OD}$ : early $\mathrm{OD}$ reflects $\mathrm{LB}$ development in the olfactory bulb. LBs are prominent neuropathological features in monogenic PD forms with OD (SNCA, GBA, PINK1, and DJ1), but not in PRKN-related PD where olfaction is preserved (28$64,70-77$ ). Progressive OD is also seen in mice expressing forms of human $\alpha$-synuclein exhibiting olfactory-bulb Lewy pathology (78, 120, 121). ATP13A2 (ATPase cation transporting 13A2) carriers exhibit OD (65) but not LB (122), but show atypical PD. Since LB and olfactory dysfunction are not always seen in LRRK2 carriers, and some LRRK2 alleles have fewer LB (40$49,76,77,123)$, additional support for this hypothesis would come if the relatively preserved olfaction in a subgroup of $L R R K 2$ carriers were also associated with fewer olfactory-bulb LB. If this hypothesis is correct, screening hyposmic individuals using PET ligands under development to image LB in the olfactory bulb (124) ${ }^{1}$ would help identify those having increased risk of developing PD-motor symptoms.

Early olfactory deficits are consistent with the olfactory vector hypothesis for PD pathogenesis and the caudo-rostral spread of LB pathology (113-115). It is interesting however, that some individuals with normal olfaction lack olfactory bulbs (125). This suggests that the establishment and maintenance of olfactory circuits has considerable functional plasticity. The projections of the olfactory tract form circuits spanning multiple cortical areas, including the entorhinal and orbitofrontal cortices and utilize multiple neurotransmitter systems (Figure 2). Therefore, olfactory-bulb pathology may not be the sole determinant of OD. As discussed below, early OD associated with olfactory bulb LB can be followed by later cholinergic denervation $(126,127)$. It will be important to address the extent to which $\mathrm{OD}$ in PD is associated with a loss of functional plasticity, whether it reflects the differential progression of the neurodegenerative process in one or multiple anatomical regions, the contributions of degenerative or compensatory changes in dopaminergic, or other neurotransmitter systems, including substance $\mathrm{P}$ and acetylcholine $(128,129)$, and how these associations relate to later motor-symptom onset and progression.

OD has significant, moderate to strong associations with nigrostriatal degeneration $(105,130,131)$. In one study, 98.7\% of PD subjects with imaging evidence of nigrostriatal dopaminergic denervation had OD (130). There, however, most still retained some olfactory function: $24.6 \%$ were anosmic and $73.2 \%$ were hyposmic $[N=183$, motor-disease duration $=6.4 \pm 4.3$ year, Hoehn and Yahr (H\&Y) stage 1-5].

\footnotetext{
${ }^{1}$ https://www.michaeljfox.org/grant/18f-labeled-alpha- synuclein-ligands-pet-
} imaging-lewy-bodies 


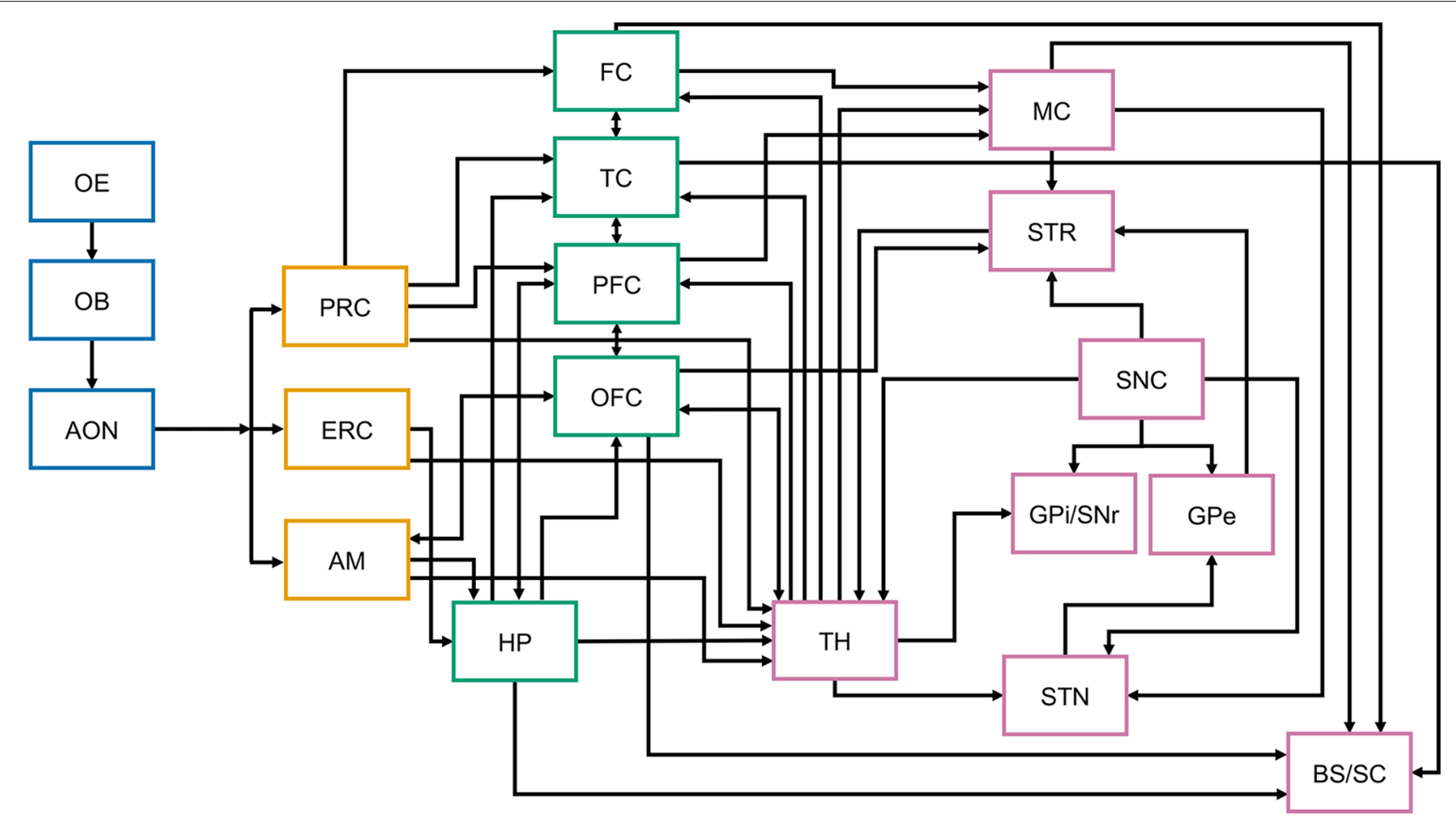

FIGURE 2 | Simplified schematic representation of central nervous system structures and connections involved in olfaction, memory, and motor control. The figure aims to illustrate the complexity of the connections of the olfactory system, associative cortices, thalamus, and the basal ganglia that may be differentially affected at different stages of Parkinson's disease. While the arrows represent anatomical and functional connectivity, not all known interconnections are included in this schematic representation. Differential neuronal loss and associated decrease in key neurotransmitter (acetylcholine, dopamine, etc.) levels at any of these structures has the potential to differentially affect their function and connectivity, thus directly and indirectly contributing to olfactory dysfunction. While in PD LB preferentially involve the brainstem at disease onset, their distribution in the olfactory and cortical areas depends on disease stage (113, 114). OE, olfactory epithelium; OB, olfactory bulb; AON, anterior olfactory nucleus; PRC, perirhinal cortex; ERC, entorhinal cortex; AM, amygdala; FC, frontal cortex; TC, temporal cortex; PFC, prefrontal cortex; OFC, orbitofrontal cortex; HP, hippocampus; TH, thalamus; MC, motor cortex; STR, striatum; SNC, substantia nigra pars compacta; GPi/SNr, globus pallidus interna/substantia nigra pars reticulata; GPe, globus pallidus externa; STN, subthalamic nucleus; BS, brainstem.

Consistent with these findings, screens for hyposmia increase the likelihood of identifying subjects with abnormal dopamine transporter binding (91). This may be a causal association or reflect coincident processes. Deficits in cholinergic transmission are a common element in OD in different diseases (132), and neurodegeneration affecting cholinergic circuits is found even early in PD [Figure 2, (133-136)]. Indeed, cholinergic denervation of the limbic archicortex in PD subjects at H\&Y 2.5 \pm 0.5 is a more robust determinant of poor odor-identification test scores than nigrostriatal dopaminergic denervation (126). When groups of PD patients having mild motor deficits and varying degrees of OD were compared, there was a more significant reduction of a putative cholinergic marker (i.e., short latency afferent inhibition of the motor cortex) when olfactory event-related potentials (a direct measure of the processing of olfactory information) were absent, than when only their latency and/or amplitude was altered (137). Curiously, a history of smoking (cholinergic stimulation) is also associated with better olfaction in PD (138).

The use of shared neural substrates in the premotor frontal and orbitofrontal cortex by olfaction and cognition (Figure 2), and the contribution of cholinergic deficits to OD provides a potential mechanism for why greater OD appears to identify the subset of sporadic and monogenic PD patients at greater risk of future cognitive impairment $[(59,107,139-149)$; reviews: (27, 150)]. Thus, genome-wide screens in PD subjects for variants that influence risk of severe OD or protect from developing OD may identify genetic factors that increase risk of, or offer protection from, cognitive impairment in PD. $\mathrm{PD}$-associated changes to central brain networks, brain-region specific structural integrity, and functional connectivity also are associated with OD (151-161). The importance of functional connectivity is highlighted by theta-specific phase coupling between the piriform cortex and hippocampus in the rapid differentiation of odor stimuli (162), and the ability of anosmic subjects having diminished functional connectivity to activate an olfaction-related functional network (163). A possible partial restoration of functional connectivity may explain why deepbrain stimulation of the subthalamic nucleus (DBS-STN) leads to modest odor-identification test score improvement (164-166). To obtain mechanistic insights into the variable presentation of OD, its relationship to motor symptom presentation and 
later cognitive dysfunction, it would be fruitful to longitudinally study carriers of monogenic PD mutations utilizing functional imaging to evaluate how functional connectivity is altered during prodromal PD and disease progression.

Since olfactory system LB increase with advancing neuropathological PD stage (113-115) and many non-motor PD symptoms such as cognitive and autonomic dysfunction often increase in severity with disease progression, it is unclear why the severity of hyposmia is not consistently associated with motor signs, disease stage, or duration. This is especially striking because the density of synuclein-pathology in the olfactory bulb is positively correlated with motor scores (165). Some cross-sectional studies reveal that diminished scores on olfactoryfunction tests are associated with increased disease duration $(167,168)$, while others do not $(22,23,25,117,148,169,170)$. Some studies have reported associations with more severe disease $(22,148,168,169,171,172)$ but others have not $(24,25,117,170,173-175)$, even though hyposmia severity is associated with lower dopamine transporter activity (168). While OD does not always develop in parallel with other non-motor symptoms in either sporadic or monogenic PD (65), resolving whether it does develop in parallel with motor symptoms has implications for management. In one study of PD subjects with similar striatal dopamine transporter activities, normosmic individuals had lower levodopa-equivalent dose requirements than did hyposmic individuals at 2.5 years of follow-up (22), suggesting that a relative lack of OD may be associated with a clinically more benign disease course.

The conflicting results about whether OD relates to disease progression might be explained if OD does not appear gradually, but rather in a stepwise irreversible manner. Variability in the occurrence of LB within the olfactory bulb could be related to the degree of inhibition of olfactory inputs (117) and/or increase in dopaminergic neurons (118). This could contribute to variable expressivity in initial OD that remains relatively stable over time, possibly due to functional plasticity. Stepwise onset could arise from the convergence of multiple failing processes. While a primary early contributor is almost certainly the loss of functionality within the olfactory bulb, later contributions could derive from other olfactory-system regions. These could include the asynchronous stepwise failure of compensatory mechanisms and/or the onset of dysfunction in circuits involved in associative processing and interpretation of smell. Joining the gradual loss of functionality in the olfactory bulb to either of these processes would lead to a stepwise onset of OD in $\mathrm{PD}$. In this scenario, different levels of OD would be observed upon breaching different functional lintels. A continuous scaledtest score distribution would be observed in a population, but longitudinally followed individuals would show stepwise score decline. Since many newly diagnosed cases are normosmic or hyposmic, whether or not an association is observed between $\mathrm{OD}$ and motor function in a cross-sectional study would depend strongly on the cohort's initial constitution.

Whether OD shows stepwise progression could be addressed by obtaining longitudinal data on OD in large PD cohorts. To date, most studies (e.g., PPMI) assess OD only at baseline. Hyposmia can be stable over periods of 2-6 years in sporadic
PD (24, 117), MAPT mutation carriers (52), and GBA mutation carriers (50). Therefore, to assess the progression of OD accurately, follow-up longer than 5 years will be necessary. A more efficient approach is to assess the progression of OD in nonmanifesting carriers from monogenic PD cohorts where disease risk is substantially increased, and the genetic cause is known. A longitudinal study using imaging methodologies able to evaluate when LB appear, the integrity of multiple neurotransmitter systems, and functional connectivity would help address the relative contribution of each to the onset and progression of OD and motor symptoms.

\section{WHAT DO OLFACTORY-FUNCTION TESTS ASSESS ABOUT THE DISEASE PROCESS?}

The stability of measurements of OD in PD suggests that it may be challenging to use them to directly assess the prodromal and symptomatic disease process outside of monogenic PD cohorts. Intriguingly, PD subjects often subjectively assess their olfactory ability as better than evaluated by validated clinical measures $(13,24,176-178)$. One study (176) found $91 \%$ hyposmic subjects using the UPSIT, an objective odor-identification test, vs. 55\% using a subject's subjective assessment. Lower scores on clinical tests have implications for a patient's quality of life. Patients unaware of their olfactory deficit may be at greater risk of harm because they may be unable to detect smoke or spoiled foods (178). However, this concern may be tempered if the perception of the patient is not fully captured by the objective assessment.

An explanation for the discrepancy between the objective and subjective assessments comes from finding that a loss of awareness of hyposmia is associated with mild cognitive impairment in PD (177). PD patients who overrate their sense of smell or are aware of their hyposmia have worse executive function than those who are objectively and subjectively normosmic (13). Memory is strongly related to olfaction, and deficits in olfaction and verbal learning/memory in PD are associated $(107,126,179-182)$. Deficits in cognitive processes also indirectly contribute to lower scores on forced-choice odor-identification tests (69). Consequently, discrepancies in the metacognitive knowledge of hyposmic individuals-selfawareness of their olfactory ability-and objectively measured OD may reflect testing-related cognitive challenges in memory or decision making. This lack of metacognitive knowledge may be a sensitive biomarker of early cognitive decline (13). A lack of metacognitive knowledge may also identify individuals whose olfactory system can have functionality restored. If a subject's perceptual reality is better than their objectively assessed ability, some of the neural substrates used for processing olfactory information should be preserved. Assessing metacognitive knowledge within longitudinal studies of monogenic PD could help identify the neural substrates preserved when metacognitive knowledge does not match objective measurements, and which are lost when individuals self-perceive anosmia. This has pragmatic considerations for managing cognitive decline.

Identifying individuals whose olfactory system could have functionality restored also identifies candidates for potential 
OD therapy. While motor symptom treatment is a primary concern in PD, improving non-motor symptoms like OD will improve patient quality of life $(13,183)$. Simple strategies to improve OD are lacking presently. While DBS-STN modestly improves OD (163-166), DBS-STN is currently used to treat motor complications of levodopa therapy in patients with an at-least 4 year disease duration. It will be informative to assess if other treatments currently under development, such as $\alpha$-synuclein antibody therapy, gene-editing therapy or other molecular treatments specific to monogenic forms of PD, also have a beneficial effect on OD.

\section{CONCLUSION}

Elucidation of the mechanisms underlying $\mathrm{OD}$ in $\mathrm{PD}$ and their relationship to the onset and progression of motor and cognitive symptoms will contribute to comprehensive measures of OD being used to better understand, identify and manage PD. Well-characterized monogenic cohorts identified within the

\section{REFERENCES}

1. Ansari KA, Johnson A. Olfactory function in patients with Parkinson's disease. J Chronic Dis. (1975) 28:493-7. doi: 10.1016/0021-9681(75)90058-2

2. Hawkes CH, Shephard BC. Olfactory evoked responses and identification tests in neurological disease. Ann N Y Acad Sci. (1998) 855:60815. doi: 10.1111/j.1749-6632.1998.tb10631.x

3. Doty RL. Olfactory dysfunction in Parkinson disease. Nat Rev Neurol. (2012) 8:329-39. doi: 10.1038/nrneurol.2012.80

4. Haehner A, Hummel T, Reichmann H. A clinical approach towards smell loss in Parkinson's disease. J Parkinsons Dis. (2014) 4:18995. doi: 10.3233/JPD-130278

5. Ottaviano G, Frasson G, Nardello E, Martini A. Olfaction deterioration in cognitive disorders in the elderly. Aging Clin Exp Res. (2016) 28:3745. doi: 10.1007/s40520-015-0380-x

6. Pardini M, Huey ED, Cavanagh AL, Grafman J. Olfactory function in corticobasal syndrome and frontotemporal dementia. Arch Neurol. (2009) 66:92-6. doi: 10.1001/archneurol.2008.521

7. McLaughlin NC, Westervelt HJ. Odor identification deficits in frontotemporal dementia: a preliminary study. Arch Clin Neuropsychol. (2008) 23:119-23. doi: 10.1016/j.acn.2007.07.008

8. Alves J, Petrosyan A, Magalhães R. Olfactory dysfunction in dementia. World J Clin Cases. (2014) 2:661-7. doi: 10.12998/wjcc.v2.i11.661

9. Moberg PJ, Doty RL. Olfactory function in Huntington's disease patients and at-risk offspring. Int $J$ Neurosci. (1997) 89:133-9. doi: 10.3109/00207459708988468

10. Ferini-Strambi L, Rinaldi F, Giora E, Marelli S, Galbiati A. REM sleep behaviour disorder. Parkinsonism Relat Disord. (2016) 22(Suppl 1):S6972. doi: 10.1016/j.parkreldis.2015.09.002

11. Meles SK, Vadasz D, Renken RJ, Sittig-Wiegand E, Mayer G, Depboylu C, et al. FDG PET, dopamine transporter SPECT, and olfaction: combining biomarkers in REM sleep behavior disorder. Mov Disord. (2017) 32:148286. doi: $10.1002 / \mathrm{mds} .27094$

12. Postuma RB, Iranzo A, Hu M, Högl B, Boeve BF, Manni R, et al. Risk and predictors of dementia and parkinsonism in idiopathic REM sleep behaviour disorder: a multicentre study. Brain. (2019) 142:74459. doi: 10.1093/brain/awz030

13. Leonhardt B, Tahmasebi R, Jagsch R, Pirker W, Lehrner J. Awareness of olfactory dysfunction in Parkinson's disease. Neuropsychology. (2019) 33:633-41. doi: 10.1037/neu0000544

14. Hummel T, Nordin S. Olfactory disorders and their consequences for quality of life. Acta Laryngol. (2005) 125:116-21. doi: 10.1080/00016480410022787
GEoPD and other international consortia (184) can serve as the ideal substrate for multifaceted longitudinal studies needed for this purpose.

\section{AUTHOR CONTRIBUTIONS}

$\mathrm{KM}$ and $\mathrm{BC}$ contributed to the conception of the review. $\mathrm{BC}$ wrote the first draft of the manuscript. BC and KM contributed to manuscript revision, read, and approved the submitted version.

\section{FUNDING}

KM receives philanthropic research support through NorthShore University Health System.

\section{ACKNOWLEDGMENTS}

The authors wish to thank Christina Chase-Markopoulou for her assistance in the preparation of Figure 2.

15. Keller A, Malaspina, D. Hidden consequences of olfactory dysfunction: a patient report series. BMC Ear Nose Throat Disord. (2013) 13:8. doi: 10.1186/1472-6815-13-8

16. Schapira AHV, Chaudhuri KR, Jenner P. Non-motor features of Parkinson disease. Nat Rev Neurosci. (2017) 18:435-50. doi: 10.1038/nrn.2017.62

17. Pfeiffer RF. Non-motor symptoms in Parkinson's disease. Parkinsonism Relat Disord. (2016) 22:S119-22. doi: 10.1016/j.parkreldis.2015.09.004

18. Xiao Q, Chen S, Le W. Hyposmia: a possible biomarker of Parkinson's disease. Neurosci Bull. (2014) 30:134-40. doi: 10.1007/s12264-013-1390-3

19. Fullard ME, Morley JF, Duda JE. Olfactory dysfunction as an early biomarker in Parkinson's disease. Neurosci Bull. (2017) 33:515-25. doi: 10.1007/s12264-017-0170-x

20. Doty RL, Hawkes CH. Chemosensory dysfunction in neurodegeneratice diseases. Handb Clin Neurol. (2019) 164:32560. doi: 10.1016/B978-0-444-63855-7.00020-4

21. Ward CD, Hess WA, Calne DB. Olfactory impairment in Parkinson's disease. Neurology. (1983) 33:943-6. doi: 10.1212/WNL.33.7.943

22. Lee DH, Joh JS, Ham JH, Lee JJ, Lee I, Lee PH, et al. Is normosmic Parkinson disease a unique clinical phenotype? Neurology. (2015) 85:12705. doi: 10.1212/WNL.0000000000001999

23. Hawkes $\mathrm{CH}$, Shephard BC, Daniel SE. Olfactory dysfunction in Parkinson's disease. J Neurol Neurosurg Psychiatry. (1997) 62:436-46. doi: 10.1136/jnnp.62.5.436

24. Doty RL, Deems DA, Stellar S. Olfactory dysfunction in Parkinson's disease, a general deficit unrelated to neurologic signs, disease stage or disease duration. Neurology. (1998) 38:1237-44. doi: 10.1212/WNL.38.8.1237

25. Haehner A, Boesveldt S, Berendse HW, Mackay-Sim A, Fleischmann J, Silburn PA, et al. Prevalence of smell loss in Parkinson's disease - a multicenter study. Parkinsonism Relat Disord. (2009) 15:4904. doi: 10.1016/j.parkreldis.2008.12.005

26. Doty RL, Kamath V. The influences of age on olfaction: a review. Front Psychol. (2014) 5:20. doi: 10.3389/fpsyg.2014.00020

27. Attems J, Walker L, Jellinger KA. Olfaction and aging: a mini-review. Gerontology. (2015) 61:485-90. doi: 10.1159/000381619

28. Markopoulou K, Larsen KW, Wszolek EK, Denson MA, Lang AE, Pfeiffer RF, et al. Olfactory dysfunction in familial parkinsonism. Neurology. (1997) 49:1262-67. doi: 10.1212/WNL.49.5.1262

29. Kruger R, Kuhn W, Müller T, Woitalla D, Graeber M, Kösel S, et al. Ala30Pro mutation in the gene encoding $\alpha$-synuclein in Parkinson's disease. Nat. Genet. (1998) 18:106-8. doi: 10.1038/ng0298-106

30. Khan NL, Jain S, Lynch JM, Pavese N, Abou-Sleiman P, Holton JL, et al. Mutations in the gene LRRK2 encoding dardarin (PARK8) cause 
familial Parkinson's disease: clinical, pathological, olfactory and functional imaging and genetic data. Brain. (2005) 128:2786-96. doi: 10.1093/brain/ awh667

31. Bostantjopoulou S, Katsarou Z, Papadimitriou A, Veletza V, Hatzigeorgiou $\mathrm{G}$, Lees A. Clinical features of parkinsonian patients with the $\alpha$ synuclein (G209A) mutation. Mov Disord. (2001) 16:1007-13. doi: 10.1002/ mds. 1221

32. Ferreira JJ, Guedes LC, Rosa MM, Coelho M, van Doeselaar M, Schweiger D, et al. High prevalence of LRRK2 mutations in familial and sporadic Parkinson's disease in Portugal. Mov Disord. (2007) 22:1194201. doi: $10.1002 / \mathrm{mds} .21525$

33. Goker-Alpan O, Lopez G, Vithayatil J, Davis J, Hallet M, Sidranski E. The spectrum of parkinsonian manifestations associated with glucocerebrosidase mutations. Arch. Neurol. (2008) 65:1353-7. doi: 10.1001/archneur.65.10.1353

34. Healy DG, Falchi M, O'Sullivan SS, Bonifati V, Durr A, Bressman S, et al. Phenotype, genotype, and worldwide genetic penetrance of LRRK2associated Parkinson's disease: a case-control study. Lancet Neurol. (2008) 7:583-90. doi: 10.1016/S1474-4422(08)70117-0

35. Lohmann E, Leclere L, De Anna F, Lesage S, Dubois B, Agid Y, et al. A clinical, neuropsychological and olfactory evaluation of a large family with LRRK2 mutations. Parkinsonism Relat Disord. (2009) 15:2736. doi: 10.1016/j.parkreldis.2008.06.008

36. Nishioka K, Ross OA, Ishii K, Kachergus JM, Ishiwata K, Kitagawa M, et al. Expanding the clinical phenotype of SNCA duplication carriers. Mov Disord. (2009) 24:1811-9. doi: $10.1002 / \mathrm{mds} .22682$

37. Silveira-Moriyama L, Guedes LC, Kingsbury A, Ayling H, Shaw $\mathrm{K}$, Barbosa ER, et al. Hyposmia in G2019S LRRK2-related parkinsonism: clinical and pathologic data. Neurology. (2008) 71:1021-6. doi: 10.1212/01.wnl.0000326575.20829.45

38. Silveira-Moriyama L, Munhoz RP, de J Carvalho M, Raskin S, Rogaeva E, de C Aguiar P, et al. Olfactory heterogeneity in LRRK2 related Parkinsonism. Mov Disord. (2010) 25:2879-83. doi: 10.1002/mds.23325

39. Saunders-Pullman R, Hagenah J, Dhawan V, Stanley K, Pastores G, Sathe S, et al. Gaucher disease ascertained through a Parkinson's center: imaging and clinical characterization. Mov Disord. (2010) 25:136472. doi: $10.1002 / \mathrm{mds} .23046$

40. Saunders-Pullman R, Mirelman A, Wang C, Alcalay RN, San Luciano M, Ortega R, et al. Olfactory identification in LRRK2 G2019S mutation carriers: a relevant marker? Ann Clin Transl Neurol. (2014) 1:6708. doi: $10.1002 / \operatorname{acn} 3.95$

41. Saunders-Pullman R, Stanley K, Wang C, San Luciano M, Shanker V, Hunt A, et al. Olfactory dysfunction in LRRK2 G2019S mutation carriers. Neurology. (2011) 77:319-24. doi: 10.1212/WNL.0b013e318227041c

42. Saunders-Pullman R, Mirelman A, Alcalay RN, Wang C, Ortega RA, Raymond D, et al. Progression in the LRRK2associated Parkinson disease population. JAMA Neurol. (2018) 75:312-9. doi: 10.1001/jamaneurol.2017.4019

43. Johansen KK, White LR, Farrer MJ, Aasly JO. Subclinical signs in LRRK2 mutation carriers. Parkinsonism Relat Disord. (2011) 17:52832. doi: $10.1016 /$ j.parkreldis.2011.04.014

44. Marras C, Schüle B, Munhoz RP, Rogaeva E, Langston JW, Kasten $\mathrm{M}$, et al. Phenotype in parkinsonian and nonparkinsonian LRRK2 G2019S mutation carriers. Neurology. (2011) 77:32533. doi: 10.1212/WNL.0b013e318227042d

45. Sierra M, Sánchez-Juan P, Martínez-Rodríguez MI, González-Aramburu I, García-Gorostiaga I, et al. Olfaction and imaging biomarkers in premotor LRRK2 G2019S-associated Parkinson disease. Neurology. (2013) 80:6216. doi: 10.1212/WNL.0b013e31828250d6

46. Gaig C, Vilas D, Infante J, Sierra M, García-Gorostiaga I, Buongiorno M, et al. Nonmotor symptoms in LRRK2 G2019S associated Parkinson's disease. PLoS One. (2014) 9:e108982. doi: 10.1371/journal.pone.01 08982

47. Johansen KK, Warø BJ, Aasly JO. Olfactory dysfunction in sporadic Parkinson's Disease and LRRK2 carriers. Acta Neurol Scand. (2014) 129:3006. doi: 10.1111/ane.12172

48. Chen W, Kang WY, Chen S, Wang Y, Xiao Q, Wang G, et al. Hyposmia correlates with SNCA variant and non-motor symptoms in Chinese patients with Parkinson's disease. Parkinsonism Relat Disord. (2015) 21:6104. doi: 10.1016/j.parkreldis.2015.03.021

49. Mirelman A, Alcalay RN, Saunders-Pullman R, Yasinovsky K, Thaler A, Gurevich T, et al. Nonmotor symptoms in healthy Ashkenazi Jewish carriers of the G2019S mutation in the LRRK2 gene. Mov Disord. (2015) 30:9816. doi: $10.1002 / \mathrm{mds} .26213$

50. Avenali M, Toffoli M, Mullin S, McNeil A, Hughes DA, Mehta A, et al. Evolution of prodromal parkinsonian features in a cohort of GBA mutation-positive individuals: a 6-year longitudinal study. $J$ Neurol Neurosurg Psychiatry. (2019) 90:1091-7. doi: 10.1136/jnnp-2019-3 20394

51. Cao M, Gu ZQ, Li Y, Zhang H, Dan XJ, Cen SS, et al. Olfactory dysfunction in Parkinson's disease patients with the LRRK2 G2385R variant. Neurosci Bull. (2016) 32:572-6. doi: 10.1007/s12264-016-0070-5

52. Markopoulou K, Chase BA, Robowski P, Strongosky A, Narozanska E, Sitek EJ, et al. Assessment of olfactory function in MAPTassociated neurodegenerative disease reveals odor-identification irreproducibility as a non-disease-specific, general characteristic of olfactory dysfunction. PLoS One. (2016) 11:e0165112. doi: 10.1371/journal.pone.01 65112

53. Papadimitriou D, Antonelou R, Miligkos M, Maniati M, Papagiannakis N, Bostantjopoulou S, et al. Motor and nonmotor features of carriers of the p.A53T alpha-synuclein mutation: a longitudinal study. Mov Disord. (2016) 31:1226-30. doi: 10.1002/mds.26615

54. Thaler A, Gurevich T, Bar Shira A, Gana Weisz M, Ash E, Shiner T, et al. A "dose" effect of mutations in the GBA gene on Parkinson's disease phenotype. Parkinsonism Relat Disord. (2017) 36:47-51. doi: 10.1016/j.parkreldis.2016.12.014

55. Thaler A, Bregman N, Gurevich T, Shiner T, Dror Y, Zmira O, et al. Parkinson's disease phenotype is influenced by the severity of the mutations in the GBA gene. Parkinsonism Relat Disord. (2018) 55:459. doi: 10.1016/j.parkreldis.2018.05.009

56. Pont-Sunyer C, Hotter A, Gaig C, Seppi K, Compta Y, Katzenschlager R, et al. The onset of nonmotor symptoms in Parkinson's disease (the ONSET PD study). Mov Disord. (2015) 30:229-37. doi: 10.1002/mds.26077

57. Kasten M, Hartmann C, Hampf J, Schaake S, Westenberger A, Vollstedt EJ, et al. Genotype-phenotype relations for the Parkinson's disease genes Parkin, PINK1, DJ1: MDSGene systematic review. Mov Disord. (2018) 33:730-41. doi: 10.1002/mds.27352

58. Sierra M, Martínez-Rodríguez I, Sánchez-Juan P, González-Aramburu I, Jiménez-Alonso M, Sánchez-Rodríguez A, et al. Prospective clinical and DaT-SPECT imaging in premotor LRRK2 G2019S-associated Parkinson disease. Neurology. (2017) 89:439-44. doi: 10.1212/WNL.0000000000 004185

59. Koros C, Stamelou M, Simitsi A, Beratis I, Papadimitriou D, Papagiannakis $\mathrm{N}$, et al. Selective cognitive impairment and hyposmia in p.A53T SNCA PD vs typical PD. Neurology. (2018) 90:e864-e9. doi: 10.1212/WNL.0000000000005063

60. Mestre TA, Pont-Sunyer C, Kausar F, Visanji NP, Ghate T, Connolly BS, et al. Clustering of motor and nonmotor traits in leucine-rich repeat kinase 2 G2019S Parkinson's disease nonparkinsonian relatives: a multicenter family study. Mov Disord. (2018) 33:960-5. doi: 10.1002/mds.27272

61. Mullin S, Beavan M, Bestwick J, McNeill A, Proukakis C, Cox T, et al. Evolution and clustering of prodromal parkinsonian features in GBA1 carriers. Mov Disord. (2019) 34:1365-73. doi: 10.1002/mds.27775

62. Narendra DP, Isonaka R, Nguyen D, Schindler AB, Kokkinis AD, Ehrlich D, et al. Peripheral synucleinopathy in a DJ1 patient with Parkinson disease, cataracts, and hearing loss. Neurology. (2019) 92:11135. doi: 10.1212/WNL.0000000000007614

63. Ferraris A, Ialongo T, Passali GC, Pellecchia MT, Brusa L, Laruffa M, et al. Olfactory dysfunction in Parkinsonism caused by PINK1 mutations. Mov Disord. (2009) 24:2350-7. doi: 10.1002/mds.22816

64. Eggers C, Schmidt A, Hagenah J, Brüggemann N, Klein JC, Tadic V, et al. Progression of subtle motor signs in PINK1 mutation carriers with mild dopaminergic deficit. Neurology. (2010) 74:1798-805. doi: 10.1212/WNL.0b013e3181e0f79c

65. Kerteige L, Brüggemann N, Schmidt A, Tadic V, Wisse C, Dankert $S$, et al. Impaired sense of smell and color discrimination in 
monogenic and idiopathic Parkinson's disease. Mov Disord. (2010) 25:2665-9. doi: 10.1002/mds.23272

66. Kasten M, Marras C, Klein C. Nonmotor signs in genetic forms of Parkinson's disease. Int Rev Neurobiol. (2017) 133:12978. doi: 10.1016/bs.irn.2017.05.030

67. Kestenbaum M, Alcalay RN. Clinical features of LRRK2 carriers with Parkinson's disease. Adv Neurobiol. (2017) 14:31-48. doi: 10.1007/978-3-319-49969-7_2

68. Lim EW, Tan EK. Genes and nonmotor symptoms in Parkinson's disease. Int Rev Neurobiol. (2017) 133:111-27. doi: 10.1016/bs.irn.2017. 05.029

69. Mertens AT, Santo JB, Markopoulou K, Chase BA. Cognitive processes that indirectly affect olfactory dysfunction in Parkinson's disease. Clin Park Rel Disord. (2019) 1:13-20. doi: 10.1016/j.prdoa.2019. 07.003

70. Khan NL, Katzenschlager R, Watt H, Bhatia KP, Wood NW, Quinn N, et al. Olfaction differentiates Parkin disease from early-onset parkinsonism and Parkinson disease. Neurology. (2004) 62:1224-6. doi: 10.1212/01.WNL.0000118281.66 802.81

71. Yoritaka A, Shimo Y, Shimo Y, Inoue Y, Yoshino H, Hattori N. Nonmotor symptoms in patients with PARK2 mutations. Parkinsons Dis. (2011) 2011:473640. doi: 10.4061/2011/473640

72. Alcalay RN, Siderowf A, Ottman R, Caccappolo E, Mejia-Santana $\mathrm{H}$, Tang $\mathrm{M}-\mathrm{X}$, et al. Olfaction in Parkin heterozygotes and compound heterozygotes: the CORE-PD study. Nerology. (2011) 76:319-26. doi: 10.1212/WNL.0b013e31820882aa

73. Sheerin U-M, Charlesworth G, Bras J, Guerreiro R, Bhatia K, Foltynie $\mathrm{T}$, et al. Screening of VPS35 mutations in Parkinson's disease. Neurobiol Aging. (2012) 33:838.e1-e5. doi: 10.1016/j.neurobiolaging.2011. 10.032

74. Malek N, Swallow DM, Grosset KA, Lawton MA, Smith CR, Bajaj NP, et al. Olfaction in Parkin single and compound heterozygotes in a cohort of young onset Parkinson's disease patients. Acta Neurol Scand. (2016) 134:271-6. doi: 10.1111/ane.12538

75. Wang Y, Wu JJ, Liu FT, Chen K, Chen C, Luo SS, et al. Olfaction in Parkin carriers in Chinese patients with Parkinson disease. Brain Behav. (2017) 7:e00680. doi: 10.1002/brb3.680

76. Poulopoulos M, Levy OA, Alcalay RN. The neuropathology of genetic Parkinson's disease. Mov Disord. (2012) 27:831-42. doi: 10.1002/mds.24962

77. Schneider SA, Alcalay RN. Neuropathology of genetic synucleinopathies with parkinsonism: review of the literature. Mov Disord. (2017) 32:150423. doi: $10.1002 / \mathrm{mds} .27193$

78. McDowell K, Chesselet MF. Animal models of the nonmotor features of Parkinson's disease. Neurobiol Dis. (2012) 46:597-606. doi: 10.1016/j.nbd.2011.12.040

79. Ponsen MM, Stoffers D, Booij J, van Eck-Smit BLF, Wolters EC, Berendse HW. Idiopathic hyposmia as a preclinical sign of Parkinson's disease. Ann Neurol. (2004) 56:173-81. doi: 10.1002/ana.20160

80. Ross GW, Petrovitch H, Abbott RD, Tanner CM, Popper J, Masaki $\mathrm{K}$, et al. Association of olfactory dysfunction with risk for future Parkinson's disease. Ann Neurol. (2008) 63:167-73. doi: 10.1002/ana. 21291

81. Doty RL. Olfaction in Parkinson's disease and related disorders. Neurobiol Dis. (2012) 46:527-52. doi: 10.1016/j.nbd.2011.10.026

82. Jennings D, Siderowf A, Stern M, Seibyl J, Eberly S, Oakes D, et al. Imaging prodromal Parkinson disease: the Parkinson associated risk syndrome study. Neurology. (2014) 83:1739-46. doi: 10.1212/WNL.0000000000 000960

83. Jennings D, Siderowf A, Stern M, Seibyl J, Eberly S, Oakes D, et al. Conversion to Parkinson disease in the PARS hyposmic and dopamine transporter-deficit prodromal cohort. JAMA Neurol. (2017) 74:93340. doi: 10.1001/jamaneurol.2017.0985

84. Bergareche A, Rodríguez-Oroz MC, Estanga A, Gorostidi A, López de Munain A, Castillo-Triviño T, et al. DAT imaging and clinical biomarkers in relatives at genetic risk for LRRK2 R1441G Parkinson's disease. Mov Disord. (2016) 31:335-43. doi: 10.1002/mds.26478
85. Oh YS, Choi JH, Kwon DY. Classification of scans without evidence of dopamine deficit (SWEDD) according to the olfactory function. Parkinsons Dis. (2016) 6:771-8. doi: 10.3233/JPD-160874

86. Pilotto A, Heinzel S, Suenkel U, Lerche S, Brockmann K, Roeben B, et al. Application of the movement disorder society prodromal Parkinson's disease research criteria in 2 independent prospective cohorts. Mov Disord. (2017) 32:1025-34. doi: 10.1002/mds. 27035

87. Nalls MA, McLean CY, Rick J, Eberly S, Hutten SJ, Gwinn K, et al. Diagnosis of Parkinson's disease on the basis of clinical and genetic classification: a population-based modelling study. Lancet Neurol. (2015) 14:1002-9. doi: 10.1016/S1474-4422(15)00178-7

88. Sui X, Zhou C, Li J, Chen L, Yang X, Li F. Hyposmia as a predictive marker of Parkinson's disease: a systematic review and meta-analysis. Biomed Res Int. (2019) 2019:3753786. doi: 10.1155/2019/3753786

89. Reichmann H, Brandt MD, Klingelhoefer L. The nonmotor features of Parkinson's disease: pathophysiology and management advances. Curr Opin Neurol. (2016) 29:467-73. doi: 10.1097/WCO.0000000000000348

90. Postuma RB. Nonmotor aspects of Parkinson's disease - How do they help diagnosis? Int Rev Neurobiol. (2017) 133:51939. doi: 10.1016/bs.irn.2017.04.002

91. Konno T, Al-Shaikh RH, Deutschländer AB, Uitti RJ. Biomarkers of nonmotor symptoms in Parkinson's disease. Int Rev Neurobiol. (2017) 133:259-89. doi: 10.1016/bs.irn.2017.05.020

92. Doty RL, Beals E, Osman A, Dubroff J, Chung I, Leon-Sarmiento FE et al. Suprathreshold odor intensity perception in early-stage Parkinson's disease. Mov Disord. (2014) 29:1208-12. doi: 10.1002/mds.25946

93. Tremblay C, Durand Martel P, Frasnelli J. Chemosensory perception is specifically impaired in Parkinson's disease. Parkinsonism Relat Disord. (2018) 57:68-71. doi: 10.1016/j.parkreldis.2018.08.002

94. Morley JF, Duda DE. Use of hyposmia and other non-motor symptoms to distinguish between drug-induced parkinsonism and Parkinson's disease. $J$ Parkinsons Dis. (2014) 4:169-73. doi: 10.3233/JPD-130299

95. Chen S, Tan HY, Wu ZH, Sun CP, He JX, Li XC, et al. Imaging of olfactory bulb and gray matter volumes in brain areas associated with olfactory function in patients with Parkinson's disease and multiple system atrophy. Eur J Radiol. (2014) 83:564-70. doi: 10.1016/j.ejrad.2013.11.024

96. Sengoku R, Matsushima S, Bono K, Sakuta K, Yamazaki M, Miyagawa S, et al. Olfactory function combined with morphology distinguishes Parkinson's disease. Parkinsonism Relat Disord. (2015) 21:771-7. doi: 10.1016/j.parkreldis.2015.05.001

97. Parvand M, Rankin CH. Is there a shared etiology of olfactory impairments in normal aging and neurodegenerative disease? J Alzheimers Dis. (2019) 73:1-21. doi: 10.3233/JAD-190636

98. Double KL, Rowe DB, Hayes M, Chan DK, Blackie J, Corbett A, et al. Identifying the pattern of olfactory deficits in Parkinson disease using the brief smell identification test. Arch Neurol. (2003) 60:5459. doi: 10.1001/archneur.60.4.545

99. Hawkes CH, Shephard BC. Selective anosmia in Parkinson's disease? Lancet. (1993) 341:435-6. doi: 10.1016/0140-6736(93)93027-X

100. Daum RF, Sekinger B, Kobal G, Lang CJ. Olfactory testing with “sniffin' sticks" for clinical diagnosis of Parkinson disease. Nervenarzt. (2000) 71:64350. doi: 10.1007/s001150050640

101. Silveira-Moriyama L, Williams D, Katzenschlager R, Lees A. Pizza, mint, and licorice: smell testing in Parkinson's disease in a UK population. Mov Disord. (2005) 20:S139. doi: 10.1002/mds.20470

102. Silveira-Moriyama L, Carvalho Mde J, Katzenschlager R, Petrie A, Ranvaud $\mathrm{R}$, Barbosa ER, et al. The use of smell identification tests in the diagnosis of Parkinson's disease in Brazil. Mov Disord. (2008) 23:232834. doi: $10.1002 / \mathrm{mds} .22241$

103. Silveira-Moriyama L, Sirisena D, Gamage P, Gamage R, de Silva R, Lees AJ. Adapting the Sniffin' sticks to diagnose Parkinson's disease in Sri Lanka. Mov Disord. (2009) 24:1229-33. doi: 10.1002/mds.22545

104. Chen W, Chen S, Kang WY, Li B, Xu ZM, Xiao Q, et al. Application of odor identification test in Parkinson's disease in China: a matched case-control study. J Neurol Sci. (2012) 316:47-50. doi: 10.1016/j.jns.2012.01.033

105. Bohnen NI, Gedela S, Kuwabara H, Constantine GM, Mathis CA, Studenski SA, et al. Selective hyposmia and nigrostriatal 
dopaminergic denervation in Parkinson's disease. J Neurol. (2007) 254:84-90. doi: 10.1007/s00415-006-0284-y

106. Lötsch J, Reichmann H, Hummel T. Different odor tests contribute differently to the evaluation of olfactory loss. Chem Senses. (2008) 33:1721. doi: $10.1093 /$ chemse/bjm 058

107. Mao CJ, Wang F, Chen JP, Yang YP, Chen J, Huang JY, et al. Odor selectivity of hyposmia and cognitive impairment in patients with Parkinson's disease. Clin Interv Aging. (2017) 12:1637-44. doi: 10.2147/CIA.S147588

108. Millar Vernetti P, Rossi M, Cerquetti D, Perez Lloret S, Merello M. Comparison of different olfactory identification patterns among Parkinson's disease patients from different countries. Chem Senses. (2016) 41:7783. doi: $10.1093 /$ chemse/bjv062

109. Morley JF, Cohen A, Silveira-Moriyama L, Lees AJ, Williams DR, Katzenschlager $\mathrm{R}$, et al. Optimizing olfactory testing for the diagnosis of Parkinson's disease: item analysis of the university of Pennsylvania smell identification test. $n p j$ Parkinsons Dis. (2018) 4:2. doi: 10.1038/s41531-017-0039-8

110. Hsieh JW, Keller A, Wong M, Jiang RS, Vosshall LB. SMELL-S and SMELL-R: olfactory tests not influenced by odor-specific insensitivity or prior olfactory experience. Proc Natl Acad Sci U S A. (2017) 114:1127584. doi: 10.1073/pnas.1711415114

111. Witt M, Bormann K, Gudziol V, Pehlke K, Barth K, Minovi A, et al. Biopsies of olfactory epithelium in patients with Parkinson's disease. Mov Disord. (2009) 24:906-14. doi: 10.1002/mds.22464

112. Durante MA, Kurtenbach S, Sargi ZB, Harbour JW, Choi R, Kurtenbach $\mathrm{S}$, et al. Single-cell analysis of olfactory neurogenesis and differentiation in adult humans. Nat Neurosci. (2020) 23:323-6. doi: 10.1038/s41593-0200587-9

113. Del Tridici K, Rüb U, De Vos RA, Bohl JR, Braak H. Where does Parkinson disease pathology begin in the brain? J Neuropathol Exp Neurol. (2002) 61:413-26. doi: 10.1093/jnen/61.5.413

114. Braak H, Del Tredici K, Rüb U, de Vos RA, Jansen Steur EN, Braak E. Staging of brain pathology related to sporadic Parkinson's disease. Neurobiol Aging. (2003) 24:197-211. doi: 10.1016/S0197-4580(02)0 0065-9

115. Braak H, Del Tredici K. Neuropathological staging of brain pathology in sporadic Parkinson's disease: Separating the wheat from the chaff. J. Parkinsons Dis. (2017) 7:S71-S85. doi: 10.3233/JPD-1 79001

116. Zapiec B, Dieriks BV, Tan S, Faull RLM, Mombaerts P, Curtis MA. A ventral glomerular deficit in Parkinson's disease revealed by whole olfactory bulb reconstruction. Brain. (2017) 130:2722-36. doi: 10.1093/brain/ awx208

117. Herting B, Schulze S, Reichmann H, Haehner A, Hummel T. A longitudinal study of olfactory function in patients with idiopathic Parkinson's disease. J Neurol. (2008) 255:367-70. doi: 10.1007/s00415-0080665-5

118. Huisman E, Uylings HB, Hoogland PV. A $100 \%$ increase of dopaminergic cells in the olfactory bulb may explain hyposmia in Parkinson's disease. Mov Disord. (2004) 19:687-92. doi: 10.1002/mds.10713

119. Mundiñano IC, Caballero MC, Ordóñez C, Hernandez M, DiCaudo C, Marcilla I, et al. Increased dopaminergic cells and protein aggregates in the olfactory bulb of patients with neurodegenerative disorders. Acta Neuropathol. (2011) 122:61-74. doi: 10.1007/s00401-0110830-2

120. Fleming SM, Tetreault NA, Mulligan CK, Hutson CB, Masliah E, Chesselet MF. Olfactory deficits in mice overexpressing human wildtype alpha-synuclein. Eur J Neurosci. (2008) 28:247-56. doi: 10.1111/j.1460-9568.2008.06346.x

121. Hansen C, Björklund T, Petit GH, Lundblad M, Murmu RP, Brundin $\mathrm{P}$, et al. A novel $\alpha$-synuclein-GFP mouse model displays progressive motor impairment, olfactory dysfunction and accumulation of $\alpha$ synuclein-GFP. Neurobiol Dis. (2013) 56:145-55. doi: 10.1016/j.nbd.2013. 04.017

122. Bras J, Verloes A, Schneider SA, Mole SE, Guerreiro RJ. Mutation of the parkinsonism gene ATP13A2 causes neuronal ceroid-lipofuscinosis. Hum Mol Genet. (2012) 21:2646-50. doi: 10.1093/hmg/dds089
123. Kalia LV, Lang AE, Hazrati LN, Fujioka S, Wszolek ZK, Dickson DW, et al. Clinical correlations with Lewy body pathology in LRRK2-related Parkinson disease. JAMA Neurol. (2015) 72:100-5. doi: 10.1001/jamaneurol.2014.2704

124. Mathis CA, Lopresti BJ, Ikonomovic MD, Klunk WE. Small-molecule PET tracers for imaging proteinopathies. Semin Nucl Med. (2017) 47:55375. doi: 10.1053/j.semnuclmed.2017.06.003

125. Weiss T, Soroka T, Gorodisky L, Shushan S, Snitz K, Weissgross R, et al. Human olfaction without apparent olfactory bulbs. Neuron. (2020) 105:3545.e5. doi: 10.1016/j.neuron.2019.10.006

126. Bohnen NI, Müller MLTM, Kotagal V, Koeppe RA, Kilbourn MA, Albin RL, et al. Olfactory dysfunction, central cholinergic integrity and cognitive impairment in Parkinson's disease. Brain. (2010) 133:174754. doi: 10.1093/brain/awq079

127. Bohnen NI, Müller MLTM. In vivo neurochemical imaging of olfactory dysfunction in Parkinson's disease. J Neural Transm. (2013) 120:5716. doi: 10.1007/s00702-012-0956-y

128. Dickson DW. Neuropathology of Parkinson disease. Parkinsonism Relat Disord. (2018) 46(Suppl 1):S30-S3. doi: 10.1016/j.parkreldis.2017. 07.033

129. Ferrer I, López-Gonzalez I, Carmona M, Dalfó E, Pujol A, Martínez A. Neurochemistry and the non-motor aspects of PD. Neurobiol Dis. (2012) 46:508-26. doi: 10.1016/j.nbd.2011.10.019

130. Haugen J, Müller ML, Kotagal V, Albin RL, Koeppe RA, Scott PJ, et al. Prevalence of impaired odor identification in Parkinson disease with imaging evidence of nigrostriatal denervation. J Neural Transm (Vienna). (2016) 123:421-4. doi: 10.1007/s00702-016-1524-7

131. Roos DS, Twisk JWR, Raijmakers PGHM, Doty RL, Berendse HW. Hyposmia as a marker of (non-)motor disease severity in Parkinson's disease. J Neural Transm (Vienna). (2019) 126:1471-8. doi: 10.1007/s00702-019-02074-0

132. Doty RL. Olfactory dysfunction in neurodegenerative diseases: is there a common pathological substrate? Lancet Neurol. (2017) 16:478-8. doi: 10.1016/S1474-4422(17)30123-0

133. Ruberg M, Rieger F, Villageois A, Bonnet AM, Agid Y. Acetylcholinesterase and butyrylcholinesterase in frontal cortex and cerebrospinal fluid of demented and non-demented patients with Parkinson's disease. Brain Res. (1986) 362:83-91. doi: 10.1016/0006-8993(86)91401-0

134. Hilker R, Thomas AV, Klein JC, Weisenbach S, Kalbe E, Burghaus L, et al. Dementia in Parkinson disease: functional imaging of cholinergic and dopaminergic pathways. Neurology. (2005) 65:1716-22. doi: 10.1212/01.wnl.0000191154.78131.f6

135. Shimada H, Hirano S, Shinotoh H, Aotsuka A, Sato K, Tanaka N, et al. Mapping of brain acetylcholinesterase alterations in Lewy body disease by PET. Neurology. (2009) 73:273-8. doi: 10.1212/WNL.0b013e3181ab2b58

136. Oh E, Park J, Youn J, Kim JS, Park S, Jang W. Olfactory dysfunction in early Parkinson's disease is associated with short latency afferent inhibition reflecting central cholinergic dysfunction. Clin Neurophysiol. (2017) 128:1061-8. doi: 10.1016/j.clinph.2017.03.011

137. Versace V, Langthaler PB, Sebastianelli L, Höller Y, Brigo F, Orioli A, et al. Impaired cholinergic transmission in patients with Parkinson's disease and olfactory dysfunction. J Neurol Sci. (2017) 377:55-61. doi: 10.1016/j.jns.2017.03.049

138. Lucassen EB, Sterling NW, Lee EY, Chen H, Lewis MM, Kong L, et al. History of smoking and olfaction in Parkinson's disease. Mov Disord. (2014) 29:1069-74. doi: 10.1002/mds.25912

139. Takeda A, Baba T, Kikuchi A, Hasegawa T, Sugeno N, Konno M, et al. Olfactory dysfunction and dementia in Parkinson's disease. J Parkinsons Dis. (2014) 4:181-7. doi: 10.3233/JPD-130277

140. Kwon KY, Kang SH, Kim M, Lee HM, Jang JW, Kim JY, et al. Nonmotor symptoms and cognitive decline in de novo Parkinson's disease. Can J Neurol Sci. (2014) 41:597-602. doi: 10.1017/cjn.2014.3

141. Fagundo $\mathrm{AB}$, Jiménez-Murcia $\mathrm{S}$, Giner-Bartolomé C, Islam MA, de la Torre R, Pastor A, et al. Modulation of higher-order olfaction components on executive functions in humans. PLoS One. (2015) 10:e0130319. doi: 10.1371/journal.pone.0130319

142. Vikdahl M, Domellöf ME, Forsgren L, Håglin L. Olfactory function, eating ability, and visceral obesity associated with MMSE three years 
after Parkinson's disease diagnosis. J Nutr Health Aging. (2015) 19:894900. doi: 10.1007/s12603-015-0573-1

143. Chahine LM, Weintraub D, Hawkins KA, Siderowf A, Eberly S, Oakes $\mathrm{D}$, et al. Cognition in individuals at risk for Parkinson's: Parkinson associated risk syndrome (PARS) study findings. Mov Disord. (2016) 31:8694. doi: $10.1002 / \mathrm{mds} .26373$

144. Domellöf ME, Lundin KF, Edström M, Forsgren L. Olfactory dysfunction and dementia in newly diagnosed patients with Parkinson's disease. Parkinsonism Relat Disord. (2017) 38:417. doi: 10.1016/j.parkreldis.2017.02.017

145. Weintraub D, Chahine LM, Hawkins KA, Siderowf A, Eberly S, Oakes D, et al. Cognition and the course of prodromal Parkinson's disease. Mov Disord. (2017) 32:1640-5. doi: 10.1002/mds.27189

146. Camargo CHF, Jobbins VA, Serpa RA, Berbetz FA, Sabatini JS, Teive HAG. Association between olfactory loss and cognitive deficits in Parkinson's disease. Clin Neurol Neurosurg. (2018) 173:120-3. doi: 10.1016/j.clineuro.2018.08.018

147. Gjerde KV, Müller B, Skeie GO, Assmus J, Alves G, Tysnes OB. Hyposmia in a simple smell test is associated with accelerated cognitive decline in early Parkinson's disease. Acta Neurol Scand. (2018) 138:50814. doi: $10.1111 /$ ane. 13003

148. Masala C, Solla P, Liscia A, Defazio G, Saba L, Cannas A, et al. Correlation among olfactory function, motors' symptoms, cognitive impairment, apathy, and fatigue in patients with Parkinson's disease. J Neurol. (2018) 265:176471. doi: 10.1007/s00415-018-8913-9

149. Yoo HS, Chung SJ, Lee YH, Ye BS, Sohn YH, Lee PH. Olfactory anosognosia is a predictor of cognitive decline and dementia conversion in Parkinson's disease. J Neurol. (2019) 266:1601-10. doi: 10.1007/s00415-019-09297-x

150. Marin C, Vilas D, Langdon C, Alobid I, López-Chacón M, Haehner A, et al. Olfactory dysfunction in neurodegenerative diseases. Curr Allergy Asthma Rep. (2018) 18:42. doi: 10.1007/s11882-018-0796-4

151. Su M, Wang S, Fang W, Zhu Y, Li R, Sheng K, et al. Alterations in the limbic/paralimbic cortices of Parkinson's disease patients with hyposmia under resting-state functional MRI by regional homogeneity and functional connectivity analysis. Parkinsonism Relat Disord. (2015) 21:698703. doi: 10.1016/j.parkreldis.2015.04.006

152. Cerasa A, Novellino F, Quattrone A. Connectivity changes in Parkinson's disease. Curr Neurol Neurosci Rep. (2016) 16:91. doi: 10.1007/s11910-016-0687-9

153. Ham JH, Lee JJ, Sunwoo MK, Hong JY, Sohn YH, Lee PH. Effect of olfactory impairment and white matter hyperintensities on cognition in Parkinson's disease. Parkinsonism Relat Disord. (2016) 24:95-9. doi: 10.1016/j.parkreldis.2015.12.017

154. Dayan E, Browner N. Alterations in striato-thalamo-pallidal intrinsic functional connectivity as a prodrome of Parkinson's disease. Neuroimage Clin. (2017) 16:313-18. doi: 10.1016/j.nicl.2017.08.003

155. Iannilli E, Stephan L, Hummel T, Reichmann H, Haehner A. Olfactory impairment in Parkinson's disease is a consequence of central nervous system decline. J Neurol. (2017) 264:1236-46. doi: 10.1007/s00415-017-8521-0

156. Wen MC, Xu Z, Lu Z, Chan LL, Tan EK, Tan LCS. Microstructural network alterations of olfactory dysfunction in newly diagnosed Parkinson's disease. Sci Rep. (2017) 7:12559. doi: 10.1038/s41598-017-12947-7

157. Heldmann M, Heeren J, Klein C, Rauch L, Hagenah J, Münte TF, et al. Neuroimaging abnormalities in individuals exhibiting Parkinson's disease risk markers. Mov Disord. (2018) 33:1412-22. doi: 10.1002/mds.27313

158. Park JW, Kwon DY, Choi JH, Park MH, Yoon HK. Olfactory dysfunctions in drug-naïve Parkinson's disease with mild cognitive impairment. Parkinsonism Relat Disord. (2018) 46:69-73. doi: 10.1016/j.parkreldis.2017.11.334

159. Yoneyama N, Watanabe H, Kawabata K, Bagarinao E, Hara K, Tsuboi $\mathrm{T}$, et al. Severe hyposmia and aberrant functional connectivity in cognitively normal Parkinson's disease. PLoS One. (2018) 13:e0190072. doi: 10.1371/journal.pone.0190072

160. Gargouri F, Gallea C, Mongin M, Pyatigorskaya N, Valabregue R, Ewenczyk C, et al. Multimodal magnetic resonance imaging investigation of basal forebrain damage and cognitive deficits in Parkinson's disease. Mov Disord. (2019) 34:516-25. doi: 10.1002/mds.27561
161. Georgiopoulos C, Witt ST, Haller S, Dizdar N, Zachrisson H, Engström $\mathrm{M}$, et al. A study of neural activity and functional connectivity within the olfactory brain network in Parkinson's disease. Neuroimage Clin. (2019) 23:101946. doi: 10.1016/j.nicl.2019.101946

162. Jiang H, Schuele S, Rosenow J, Zelano C, Parvizi J, Tao JX, et al. Theta oscillations rapidly convey odor-specific content in human piriform cortex. Neuron. (2017) 94:207-19.e4. doi: 10.1016/j.neuron.2017.03.021

163. Kollndorfer K, Jakab A, Mueller CA, Trattnig S, Schöpf V. Effects of chronic peripheral olfactory loss on functional brain networks. Neuroscience. (2015) 310:589-99. doi: 10.1016/j.neuroscience.2015.09.045

164. Guo X, Gao G, Wang X, Li L, Li W, Liang Q, et al. Effects of bilateral deep brain stimulation of the subthalamic nucleus on olfactory function in Parkinson's disease patients. Stereotact Funct Neurosurg. (2008) 86:23744. doi: $10.1159 / 000131662$

165. Cury RG, Carvalho MJ, Lasteros FJL, Dias AE, Dos Santos Ghilardi MG, Paiva ARB, et al. Effects of subthalamic stimulation on olfactory function in Parkinson disease. World Neurosurg. (2018) 114:e559e64. doi: 10.1016/j.wneu.2018.03.033

166. Saatçi Ö, Yilmaz NH, Zirh A, Yulug B. The therapeutic effect of deep brain stimulation on olfactory functions and clinical scores in Parkinson's disease. J Clin Neurosci. (2019) 68:55-61. doi: 10.1016/j.jocn.2019.07.055

167. Beach TG, White CL, Hladik CL, Sabbagh MN, Connor DJ, Shill HA, et al. Olfactory bulb alpha-synucleinopathy has high specificity and sensitivity for Lewy body disorders. Acta Neuropathol. (2009) 117:16974. doi: 10.1007/s00401-008-0450-7

168. Deeb J, Shah M, Muhammed N, Gunasekera R, Gannon K, Findley LJ, et al. A basic smell test is as sensitive as a dopamine transporter scan: comparison of olfaction, taste and DaTSCAN in the diagnosis of Parkinson's disease. QJM. (2010) 103:941-52. doi: 10.1093/qjmed/hcq142

169. Cavaco S, Gonçalves A, Mendes A, Viala-Chã N, Moreira I, Fernandes J, et al. Abnormal olfaction in Parkinson's disease is related to faster disease progression. Behav Neurol. (2015) 2015:976589. doi: 10.1155/2015/976589

170. Vengalil S, Agadi JB, Raghavendra K. University of Pennsylvania smell identification abnormalities in Parkinson's disease. J Assoc Physicians India. (2016) 64:32-6.

171. Tissingh G, Berendse HW, Bergmans P, DeWaard R, Drukarch B, Stoof JC, et al. Loss of olfaction in de novo and treated Parkinson's disease: possible implications for early diagnosis. Mov Disord. (2001) 16:416. doi: 10.1002/1531-8257(200101)16:1<41::AID-MDS1017>3.0.CO;2-M

172. Jalali MM, Roudbary SA, Gerami H, Soleimani R, Ebrahimi SM. Olfactory identification among various subtypes of Parkinsons disease. Eur Neurol. (2019) 81:167-73. doi: 10.1159/000501551

173. Ramjit AL, Sedig L, Leibner J, Wu SS, Dai Y, Okun MS, et al. The relationship between anosmia, constipation, and orthostasis and Parkinson's disease duration: results of a pilot study. Int J Neurosci. (2010) 120:6770. doi: 10.3109/00207450903337721

174. Siderowf A, Newberg A, Chou KL, Lloyd M, Colcher A, Hurtig $\mathrm{HI}$, et al. $\left[{ }^{99 \mathrm{~m}} \mathrm{Tc}\right]$ TRODAT-1 SPECT imaging correlates with odor identification in early Parkinson disease. Neurology. (2005) 64:171620. doi: 10.1212/01.WNL.0000161874.52302.5D

175. Boesveldt S, Verbaan D, Knol DL, Visser M, van Rooden SM, van Hilten JJ, et al. A comparative study of odor identification and odor discrimination deficits in Parkinson's disease. Mov Disord. (2008) 23:198490. doi: 10.1002/mds.22155

176. Passali GC, Bove F, Vargiu L, Bentivoglio AR, Anzivino R, De Corso E, et al. New olfactometric findings in Parkinson's disease. Clin Otolaryngol. (2017) 42:837-43. doi: 10.1111/coa.12816

177. Kawasaki I, Baba T, Takeda A, Mori E. Loss of awareness of hyposmia is associated with mild cognitive impairment in Parkinson's disease. Parkinsonism Relat Disord. (2016) 22:74-9. doi: 10.1016/j.parkreldis.2015.11.015

178. White TL, Sadikot AF, Djordjevic J. Metacognitive knowledge of olfactory dysfunction in Parkinson's disease. Brain Cogn. (2016) 104:1-6. doi: 10.1016/j.bandc.2016.01.004

179. Wilson DA, Stevenson RJ. The fundamental role of memory in olfactory perception. Trends Neurosci. (2003) 26:2437. doi: $10.1016 / \mathrm{S} 0166-2236(03) 00076-6$ 
180. de Gennes, P-G. Organization of a primitive memory: olfaction. Proc Natl Acad Sci U S A. (2004) 101:15778-81. doi: 10.1073/pnas.04038 68101

181. Aqrabawi AJ, Kim JC. Hippocampal projections to the anterior olfactory nucleus differentially convey spatiotemporal information during episodic odour memory. Nat Commun. (2018) 9:2735. doi: 10.1038/s41467-018-05131-6

182. Postuma R, Gagnon JF. Cognition and olfaction in Parkinson's disease. Brain. (2010) 133:e160. doi: 10.1093/brain/awq225

183. Dafsari HS, Weiß L, Silverdale M, Rizos A, Reddy P, Ashkan K, et al. Short-term quality of life after subthalamic stimulation depends on nonmotor symptoms in Parkinson's disease. Brain Stimul. (2018) 11:86774. doi: $10.1016 /$ j.brs.2018.02.015

184. Vollstedt EJ, Kasten M, Klein C, MJFF Global Genetic Parkinson's Disease Study Group. Using global team science to identify genetic Parkinson's disease worldwide. Ann Neurol. (2019) 86:153-7. doi: 10.1002/ana. 25514

Conflict of Interest: The authors declare that the research was conducted in the absence of any commercial or financial relationships that could be construed as a potential conflict of interest.

The handling editor declared a past collaboration with the authors.

Copyright $\odot 2020$ Chase and Markopoulou. This is an open-access article distributed under the terms of the Creative Commons Attribution License (CC BY). The use, distribution or reproduction in other forums is permitted, provided the original author(s) and the copyright owner(s) are credited and that the original publication in this journal is cited, in accordance with accepted academic practice. No use, distribution or reproduction is permitted which does not comply with these terms. 